\title{
A Novel Simple Method for Resolving Overlapped Spectral Data with A Wide Range of Applicability, and Its Application as a Stability Indicating Method for Determination of Tazarotene
}

\author{
Eman S Elzanfaly, Ahmed S Saad* and Abd-Elaziz B Abd-Elaleem \\ Analytical Chemistry Department, Faculty of Pharmacy, Cairo University, Kasr-El Aini street, 11562 Cairo, Egypt
}

\begin{abstract}
Smart simple spectrophotometric method was developed for simultaneous determination of compounds with interfering spectra in binary mixtures without previous separation. The proposed method showed significant advantages over the conventional methods regarding minimal data manipulation and applicability. The new method is based on a modification for the ratio subtraction and derivative ratio methods. This modification enabled wider range of application. The proposed method was applied for the determination of tazarotene and its alkaline degradation product in laboratory prepared mixtures with mean percentage recoveries $99.68 \pm 1.36$ and $100.86 \pm$ 1.09 respectively. The suggested method was validated according to USP guidelines and can be applied for routine quality control testing
\end{abstract}

Keywords: Spectrophotometry; Binary mixtures; Tazarotene; Stability indicating method; Alkaline degradation product and Ratio Difference method; $\Delta \mathrm{P}$ method

\section{Introduction}

Many methods have been proposed for the analysis of binary mixtures among which the spectrophotometric based methods were the most simple, fast and applicable in almost all laboratories. Several manipulations were performed on the raw overlapping spectral data to enable mixture resolution for example, using different order derivatives [1-6], derivatives of the ratio spectrum [7-9] and ratio subtraction technique [10].

The aim of the present work was to develop a new simple, rapid, selective method for the simultaneous determination of components having overlapping spectra in binary mixtures, having the advantages of minimal data processing and wider range of application over the previously mentioned methods.

To prove the ability of the newly described method in resolving the overlapping spectral data and simultaneous determination of each component, it was applied for the analysis of a mixture of tazarotene $(\mathrm{Tz})$ and its alkaline degradation product (Deg).

Tazarotene gel is used as monotherapy or in combination with other medications, such as topical corticosteroids, for the treatment of localized plaque psoriasis [11].

\section{Theory}

The method is based on the fact that upon dividing the absorption spectrum of a compound by another spectrum of the same compound, a straight line of constant amplitude (parallel to the baseline) will result. While upon dividing the absorption spectrum of a compound by the absorption spectrum of another compound, a new spectrum (ratio spectrum) will result, (Figures 1 and 2). This represents the same basis of derivative ratio and ratio subtraction methods. The difference will be in the manipulation of the resulting data.

In derivative ratio technique the following step would be applying a certain order derivative, while in ratio subtraction technique it will be followed by subtraction of a constant at a certain wavelength then multiplication with the same divisor. The developed method has the advantage of being simpler, as the following step will simply be calculating the difference between any two points in the ratio spectrum.

Mathematically it can be explained as follows:

In the ratio spectrum of a lab mixture of $\mathrm{X}$ and $\mathrm{Y}$ divided by a divisor Y'

$$
\begin{aligned}
& \mathrm{P}_{1}=\mathrm{P}_{1 \mathrm{X}}+\mathrm{K} \\
& \mathrm{P}_{2}=\mathrm{P}_{2 \mathrm{X}}+\mathrm{K}
\end{aligned}
$$

Where, $\mathrm{P}_{1}$ and $\mathrm{P}_{2}$ are the amplitudes of the mixture spectrum at $\lambda_{1}$ and $\lambda_{2}$, respectively.

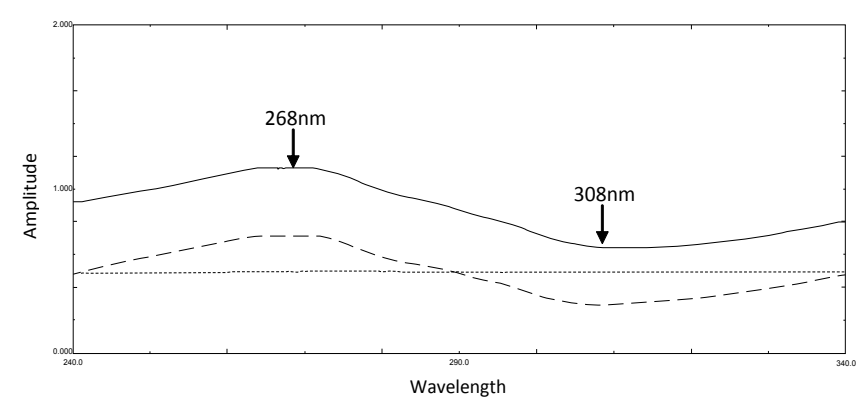

Figure 1: The raio spectra of $5 \mu \mathrm{g} / \mathrm{ml} \mathrm{Tz} \mathrm{(---),} 5 \mu \mathrm{g} / \mathrm{ml}$ Deg (...) and a mixture containing $5 \mu \mathrm{g} / \mathrm{ml} \mathrm{Tz}$ and $5 \mu \mathrm{g} / \mathrm{ml}$ Deg (_), using a divisor of $10 \mu \mathrm{g} / \mathrm{ml} \mathrm{Deg}$ as a divisor.

*Corresponding author: Ahmed S Saad, Analytical Chemistry Department Faculty of Pharmacy, Cairo University, Kasr-El Aini street, 11562 Cairo, Egypt, E-mail: ahmedss_pharm@yahoo.com

Received January 20, 2012; Accepted April 21, 2012; Published April 23, 2012

Citation: Elzanfaly ES, Saad AS, Abd-Elaleem AEB (2012) A Novel Simple Method for Resolving Overlapped Spectral Data with A Wide Range of Applicability, and Its Application as a Stability Indicating Method for Determination of Tazarotene. Pharmaceut Anal Acta 3:153. doi:10.4172/2153-2435.1000153

Copyright: (C) 2012 Elzanfaly ES, et al. This is an open-access article distributed under the terms of the Creative Commons Attribution License, which permits unrestricted use, distribution, and reproduction in any medium, provided the original author and source are credited. 
Citation: Elzanfaly ES, Saad AS, Abd-Elaleem AEB (2012) A Novel Simple Method for Resolving Overlapped Spectral Data with A Wide Range of Applicability, and Its Application as a Stability Indicating Method for Determination of Tazarotene. Pharmaceut Anal Acta 3:153. doi:10.4172/2153-2435.1000153

Page 2 of 4

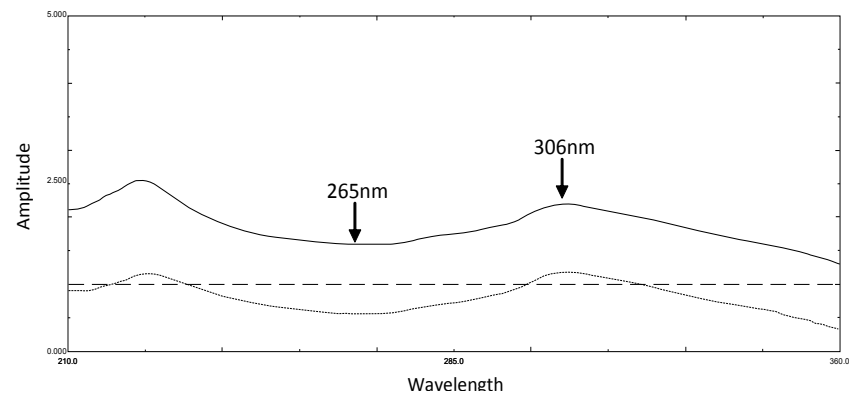

Figure 2: The raio spectra of $5 \mu \mathrm{g} / \mathrm{ml} \mathrm{TZ}(---), 5 \mu \mathrm{g} / \mathrm{ml}$ Deg (...) and a mixture containing $5 \mu \mathrm{g} / \mathrm{ml} \mathrm{TZ}$ and $5 \mu \mathrm{g} / \mathrm{ml}$ Deg (_), using a divisor of $5 \mu \mathrm{g} / \mathrm{ml} \mathrm{Tz}$ as a divisor.

$\mathrm{P}_{1 \mathrm{X}}$ and $\mathrm{P}_{2 \mathrm{X}}$ are the amplitudes of $\mathrm{X}$ at $\lambda_{1}$ and $\lambda_{2}$, respectively.

$\mathrm{K}$ is the constant resulting from $\mathrm{Y} / \mathrm{Y}^{\prime}$

$$
\Delta \mathrm{P}_{\lambda 1-\lambda 2}=\mathrm{P}_{1}-\mathrm{P}_{2}=\left(\mathrm{P}_{1 \mathrm{X}}+\mathrm{K}\right)-\left(\mathrm{P}_{2 \mathrm{X}}+\mathrm{K}\right)=\mathrm{P}_{1 \mathrm{X}}-\mathrm{P}_{2 \mathrm{X}}
$$

So the component $\mathrm{Y}$ will be completely cancelled and the difference will represent the $\mathrm{X}$ component only.

A calibration curve constructed relating the difference in amplitudes in the ratio spectrum at $\lambda_{1}$ and $\lambda_{2}\left(\Delta \mathrm{P}_{\lambda_{1-\lambda 2}}\right)$ using a certain concentration of $\mathrm{Y}$ as a divisor to the corresponding concentration of $\mathrm{X}$, regression equation is computed for the determination of $\mathrm{X}$ in the unknown samples of the binary mixture.

Similarly component $\mathrm{Y}$ can be obtained by using certain concentration of $\mathrm{X}$ as a divisor.

\section{Experimental}

\section{Apparatus}

SHIMADZU UV- 1601 PC, dual beam UV-visible spectrophotometer with two matched $1 \mathrm{~cm}$ quartz cells, connected to an IBM compatible personal computer (PC) and a HP-600 inkjet printer. Bundled UV-PC personal spectroscopy software version (3.7) was used to process the absorption and the derivative spectra. The spectral band width was $0.2 \mathrm{~nm}$ with wavelength scanning speed of $2800 \mathrm{~nm} \cdot \mathrm{min}^{-1}$.

\section{Reference samples}

Tazarotene was kindly supplied by Marcyrl Pharmaceuticals and Chemical Industries Company (Cairo, Egypt).

\section{Pharmaceutical formulation}

Acnitaz gel, labeled to contain $0.1 \mathrm{~g} \%$ Tazarotene, batch number 85332, manufactured by Marcyrl Pharmaceuticals and Chemical Industries Company, Cairo, Egypt.

\section{Materials and reagents}

1. All chemicals used were of analytical grade and solvent are of spectroscopic gradMethanol (Adwic).

2. Potassium hydroxide (1 M methanolic solution) (Adwic).

\section{Preparation of the degradation product of tazarotene}

$50 \mathrm{mg}$ of pure TZ was accurately weighed and dissolved in $25 \mathrm{ml}$ methanol and $25 \mathrm{ml} 1 \mathrm{M} \mathrm{KOH}$, then reflux the solution at $100^{\circ} \mathrm{C}$ for 30 minutes. The time required for complete degradation was followed by spotting on TLC plates at 5 minutes intervals for 30 minutes. The plates was developed using benzene: chloroform: ammonia (5: 5: 0.01 by volume) till complete degradation $[10,12]$

The degraded solution was applied as a band onto several preparative TLC plates. The plates were developed using the aforementioned solvent system in chromatographic tank previously saturated for 30 minutes with the developing solvents and then dried in air.

The bands were visualized under UV light at $254 \mathrm{~nm}$, then the bands were scraped and the silica was suspended in the least amount of methanol. Filtered and filtrate was left to dry at room temperature $\left(25^{\circ} \mathrm{C}\right)$ to obtain the degradation product. The purity of the degradation product obtained was tested by dissolving a small portion in methanol, applying onto TLC plates and developing using the previously mentioned solvent system. The structure of the isolated degradation product was elucidated using IR and mass spectrometry.

\section{Standard solutions}

1. Tz standard stock solution; $20.0 \mu \mathrm{g} / \mathrm{ml}$ in methanol

2. Deg standard stock solution; $20.0 \mu \mathrm{g} / \mathrm{ml}$ in methanol

\section{Procedures}

\section{Construction of calibration curves}

Calibration curve of Tz: Aliquots $(0.5-5.0 \mathrm{ml})$ of Tz stock solution $(20 \mu \mathrm{g} / \mathrm{ml})$ were transferred into a series of $10 \mathrm{ml}$ volumetric flasks, and the volume was completed with distilled water. The zero order spectra of the prepared solutions were divided by the spectrum of $10 \mu \mathrm{g} / \mathrm{ml}$ Deg. The peak amplitudes of the ratio spectra were measured at 268 and $308 \mathrm{~nm}$.

Calibration graphs relating the $\Delta \mathrm{P}_{268-308 \mathrm{~nm}}$ to the corresponding concentrations of $\mathrm{Tz}$ were constructed, and the corresponding regression equation was computed.

Calibration curve of Deg: Aliquots $(0.5-5.0 \mathrm{ml})$ of Deg stock solution $(20 \mu \mathrm{g} / \mathrm{ml})$ were transferred into a series of $10 \mathrm{ml}$ volumetric flasks, and the volume was completed with distilled water. The zero order spectra of the prepared solutions were divided by the spectrum of $5 \mu \mathrm{g} / \mathrm{ml} \mathrm{Tz}$. The peak amplitudes of the ratio spectra were measured at 306 and $265 \mathrm{~nm}$.

Calibration graphs relating $\Delta \mathrm{P}_{306-265 \mathrm{~nm}}$ to the corresponding concentrations of Deg were constructed, and the corresponding regression equation was computed.

\section{Analysis of laboratory prepared mixtures}

Laboratory prepared mixtures containing different ratios of $\mathrm{Tz}$ and Deg were prepared, the zero order spectrum of each laboratory prepared mixture was first divided by the spectrum of $10 \mu \mathrm{g} / \mathrm{ml}$ Deg and $\Delta \mathrm{P}_{268-308 \mathrm{~nm}}$ was calculated to determine tazarotene, after substitution in the corresponding regression equation.

The zero order spectra were then divided by the spectrum of $30 \mu \mathrm{g} /$ $\mathrm{ml} \mathrm{Tz}$ and $\Delta \mathrm{P}_{306-265 \mathrm{~nm}}$ was calculated to determine alkaline degradation product, after substitution in the corresponding regression equation.

\section{Application of the proposed method as a stability indicating method for $\mathrm{Tz}$ in acnitaz gel}

$0.5 \mathrm{gm}$ gel was accurately weighed into a $100 \mathrm{ml}$ beaker and sonicated in $15 \mathrm{ml}$ methanol for 10 minutes, filtered into $50 \mathrm{ml}$ 
Citation: Elzanfaly ES, Saad AS, Abd-Elaleem AEB (2012) A Novel Simple Method for Resolving Overlapped Spectral Data with A Wide Range of Applicability, and Its Application as a Stability Indicating Method for Determination of Tazarotene. Pharmaceut Anal Acta 3:153. doi:10.4172/2153-2435.1000153

Page 3 of 4

volumetric flask. The residue was washed three times each using $10 \mathrm{ml}$ methanol and completed to the mark with the same solvent. Transfer accurately $4 \mathrm{ml}$ of the extracted solution into a $10 \mathrm{ml}$ measuring flask. The procedure was completed as described under calibration curve.

The validity of the method was assessed by applying the standard addition technique.

\section{Results and Discussion}

A simple spectrophotometric method was developed for the simultaneous determination of the components in binary mixtures with overlapping spectra without previous separation. The binary mixture of $\mathrm{Tz}$ and Deg was chosen as an example for the application of the new method.

The absorption spectra of $\mathrm{Tz}$ and Deg show high degree of interference as shown in figure 3 , that the application of the direct spectrophotometry failed to determine either of them in their mixture.

The suggested method starts by scanning zero order spectra of the prepared standard solutions of $\mathrm{Tz}$ and Deg in distilled water. Different divisor concentrations of Deg and $\mathrm{Tz}$ were tried, for the determination of $\mathrm{Tz}$ and Deg, respectively, followed by the careful choice of the wavelength couple to correlate their differences in amplitudes $\Delta \mathrm{P}$ to their corresponding concentrations.

Careful choice of the divisor is mandatory; the selected divisors should compromise between minimal noise and maximum sensitivity. The divisor concentrations $10 \mu \mathrm{g} / \mathrm{ml}$ Deg and $5 \mu \mathrm{g} / \mathrm{ml} \mathrm{Tz}$ gave the best results regarding average recovery percent when used for the prediction of $\mathrm{Tz}$ and Deg concentrations, respectively.

Different wavelengths were chosen on the ratio spectra of the two drugs and the linearity at those wavelengths singly was assessed. A good linearity at 268 and $308 \mathrm{~nm}$ for Tz, and at 306 and $265 \mathrm{~nm}$ for Deg was obtained, (Table 1).

A linear correlation was obtained between $\Delta \mathrm{P}_{268-308 \mathrm{~nm}}$ and $\Delta \mathrm{P}_{268-308 \mathrm{~nm}}$ ' against the corresponding concentration of $\mathrm{Tz}$ and Deg, respectively (Table 2).

The proposed method was successfully applied for the simultaneous

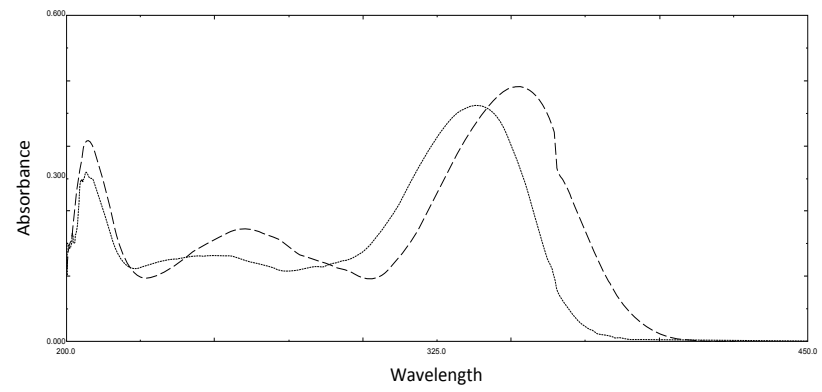

Figure 3: The absorption spectra of $5 \mu \mathrm{g} / \mathrm{ml} \mathrm{Tz}(---)$ and $5 \mu \mathrm{g} / \mathrm{ml}$ Deg (...) in methanol.

\begin{tabular}{|l|l|l|l|l|l|}
\hline \multicolumn{2}{|l|}{ Wavelength (nm) } & $\mathbf{2 6 8}$ & $\mathbf{3 0 8}$ & $\mathbf{3 0 6}$ & $\mathbf{2 6 5}$ \\
\hline $\mathrm{r}$ & Tz & 0.9997 & 0.9995 & & \\
\cline { 2 - 4 } & Deg & & & 0.9996 & 0.9993 \\
\hline
\end{tabular}

Table 1: Correlation coefficients ( $r$ ) at different wavelengths on the ratio spectrum of Tz and Deg.

\begin{tabular}{|l|c|c|}
\hline \multicolumn{1}{|c|}{ Parameter } & Tz & Deg \\
\hline Accuracy (mean \pm SD) & $100.16 \pm 1.17$ & $99.77 \pm 1.52$ \\
\hline Specificity & $99.68 \pm 1.36$ & $100.86 \pm 1.09$ \\
\hline Precision & & \\
\hline Repeatability * & $99.59 \pm 0.46$ & $100.62 \pm 0.55$ \\
\hline Intermediate precision ${ }^{* *}$ & $99.84 \pm 0.55$ & $100.78 \pm 0.95$ \\
\hline Linearity & & \\
\hline Wavelengths & 268 and $308 \mathrm{~nm}$ & 306 and $265 \mathrm{~nm}$ \\
\hline Slope & 0.0833 & 0.1186 \\
\hline Intercept & -0.0089 & 0.0094 \\
\hline Correlation coefficient $(\mathrm{r})$ & 0.9998 & 0.9998 \\
\hline Range & $1-10 \mu \mathrm{g} / \mathrm{ml}$ & $1-10 \mu \mathrm{g} / \mathrm{ml}$ \\
\hline
\end{tabular}

Table 2: Assay validation sheet of the proposed methods for the determination of Tz and Deg.

\begin{tabular}{|c|c|c|c|}
\hline \multicolumn{2}{|c|}{ Concentration $\mu \mathrm{g} / \mathrm{ml}$} & \multirow{2}{*}{$\begin{array}{l}\text { Recovery } \% \text { of Tz } \\
268-308 \mathrm{~nm}\end{array}$} & \multirow{2}{*}{$\begin{array}{l}\begin{array}{l}\text { Recovery \% } \\
\text { of Deg }\end{array} \\
306-265 \mathrm{~nm} \\
\end{array}$} \\
\hline Tz & Deg & & \\
\hline 9.00 & 1.00 & 99.92 & 102.21 \\
\hline 8.00 & 2.00 & 101.78 & 101.87 \\
\hline 7.00 & 3.00 & 98.96 & 100.56 \\
\hline 6.00 & 4.00 & 101.35 & 101.22 \\
\hline 5.00 & 5.00 & 100.31 & 102.28 \\
\hline 4.00 & 6.00 & 99.89 & 99.50 \\
\hline 3.00 & 7.00 & 98.70 & 100.58 \\
\hline 2.00 & 8.00 & 98.58 & 100.05 \\
\hline 1.00 & 9.00 & 97.59 & 99.52 \\
\hline \multicolumn{2}{|l|}{ Mean } & 99.68 & 100.86 \\
\hline \multicolumn{2}{|l|}{ Std } & 1.36 & 1.09 \\
\hline \multicolumn{2}{|l|}{ RSD \% } & 1.36 & 1.08 \\
\hline
\end{tabular}

Table 3: Determination of $\mathrm{Tz}$ and Deg in laboratory prepared mixtures by the proposed method.

\begin{tabular}{|c|c|c|c|c|c|}
\hline \multirow[b]{2}{*}{ Product } & \multirow{2}{*}{$\begin{array}{l}\text { Proposed } \\
\text { Method }\end{array}$} & \multicolumn{4}{|c|}{ Standard addition } \\
\hline & & $\begin{array}{l}\text { Taken } \\
\mu \mathrm{g} / \mathrm{ml}\end{array}$ & $\begin{array}{c}\text { Added } \\
\mu \mathrm{g} / \mathrm{ml}\end{array}$ & \begin{tabular}{|l|} 
Found \\
$\mu \mathrm{g} / \mathrm{ml}$
\end{tabular} & Recovery \% \\
\hline \multirow{6}{*}{$\begin{array}{c}\text { Tz in } \\
\text { Acnitaz® gel } \\
0.1 \mathrm{~g} \% \mathrm{Tz}\end{array}$} & \multirow{6}{*}{$101.74 \pm 1.22$} & \multirow{3}{*}{4.00} & 2.00 & 2.04 & 102.00 \\
\hline & & & 4.00 & 3.90 & 97.50 \\
\hline & & & 6.00 & 6.08 & 101.33 \\
\hline & & Mean & \multicolumn{3}{|c|}{100.28} \\
\hline & & SD & \multicolumn{3}{|c|}{2.43} \\
\hline & & RSD $\%$ & \multicolumn{3}{|c|}{2.42} \\
\hline
\end{tabular}

Table 4: Determination of Tz and Deg in Acnitaz ${ }^{\circledR}$ gel by the proposed method and application of standard addition technique.

determination of $\mathrm{Tz}$ and Deg in laboratory prepared mixtures containing different ratios of $\mathrm{Tz}$ and Deg. The mean percentage recoveries and standard deviations were shown in Table 3.

The suggested method was found to be applicable and valid for the analysis of Acnitaz gel with no interference of the excipients. The validity of the proposed procedure was assessed by applying the standard addition technique (Table 4).

The validation parameters according to USP guidelines [13] of accuracy, repeatability and intermediate precision are presented in table 2 . The data showed that the results obtained by the new method 
Citation: Elzanfaly ES, Saad AS, Abd-Elaleem AEB (2012) A Novel Simple Method for Resolving Overlapped Spectral Data with A Wide Range of Applicability, and Its Application as a Stability Indicating Method for Determination of Tazarotene. Pharmaceut Anal Acta 3:153. doi:10.4172/2153-2435.1000153

Page 4 of 4

are accurate, precise, robust and specific over the specified range.

* The intraday $(\mathrm{n}=3)$, average of three concentrations $(4,5,6 \mu \mathrm{g} /$ $\mathrm{ml})$ for $\mathrm{Tz}$ and $(4,5,6 \mu \mathrm{g} / \mathrm{ml})$ for Deg repeated three times within the day.

** The interday $(\mathrm{n}=3)$, average of three concentrations $(4,5,6 \mu \mathrm{g} /$ $\mathrm{ml})$ for $\mathrm{Tz}$ and $(4,5,6 \mu \mathrm{g} / \mathrm{ml})$ for Deg repeated three times in three successive days.

The suggested method was able to determine either component in the binary mixture without limitations, whereas the ratio subtraction method [10] can only determine the component with the less extended spectrum, therefore enabling a wider range of application.

\section{Conclusion}

The present work described a simple method for manipulating overlapped spectral data for simultaneous determination of compounds in binary mixtures. The method was successfully applied for simultaneous determination of $\mathrm{Tz}$ and Deg in pure powder form and in pharmaceutical formulation. The method was validated and showed that it can be used for the regular quality control testing due to its simplicity and wide range of applicability.

\section{References}

1. Altinöz S, Tekeli D (2001) Analysis of glimepiride by using derivative UV spectrophotometric method. J Pharm Biomed Anal 24: 507-515.

2. Bonazzi D, Gotti R, Andrisano V, Cavrini V (1997) Analysis of ACE inhibitors in pharmaceutical dosage forms by derivative UV spectroscopy and liquid chromatography (HPLC). J Pharma Biomed Anal 16: 431-438.

3. Challa BR, Awen BZ, Chandu BR, Khagga M, Kotthapalli CB (2010) Method development and validation of montelukast in human plasma by HPLC coupled with ESI-MS/MS: application to a bioequivalence study. Sci Pharm 78: 411 422

4. Erk N (2002) Spectrophotometric analysis of valsartan and hydrochlorothiazide Anal Lett 35: 283-302.

5. Lemus Gallego JM, Perez Arroyo P (2001) Simultaneous resolution of dexamethasone and polymyxin $b$ by spectrophotometry derivative and multivariate methods. Anal Lett 34: 1265-1283.

6. Nanda RK, Pangarkar VB, Thomas AB, Kothapalli LP, Pawar AA (2008) Simultaneous estimation of Montelukast sodium and Bambuterol hydrochloride in tablets by spectrophotometry. Hindustan Antibiotic Bull 49-50: 29-33.

7. Darwish HW, Hassan SA, Salem MY, El-Zeiny BA (2011) Three different spectrophotometric methods manipulating ratio spectra for determination of binary mixture of Amlodipine and Atorvastatin. Spectrochim Acta A Mol Biomol Spectrosc 83: 140-148.

8. Hassib ST, El-Zaher AA, Fouad MA (2011) Validated stability-indicating derivative and derivative ratio methods for the determination of some drugs used to alleviate respiratory tract disorders and their degradation products. Drug Test Anal 3: 306-318.

9. Salinas F, Nevado JJ, Mansilla AE (1990) A new spectrophotometric method for quantitative multicomponent analysis resolution of mixtures of salicylic and salicyluric acids. Talanta 37: 347-351.

10. El-Bardicy MG, Lotfy HM, El-Sayed MA, El-Tarras MF (2008) Smart stabilityindicating spectrophotometric methods for determination of binary mixtures without prior separation. J AOAC Int 91: 299-310.

11. Gilman AC, Rall TW, Nies AS, Tayor P (2001) Goodman and Gilman's The Pharmacological Basis of Therapeutics. (10thedn), Pergamon Press, New York, USA.

12. Badawy AM, El-Alim Ael-A, Saad AS (2010) Stability-indicating spectrophotometric methods for determination of tazarotene in the presence of its alkaline degradation product by derivative spectrophotometric techniques. Drug Test Anal 2: 130-136.

13. The United States Pharmacopoeia and National Formulary (USP 28-NF 23) (2005) Asian edn., United States Pharmacopeia Convention Inc., Rockville. 